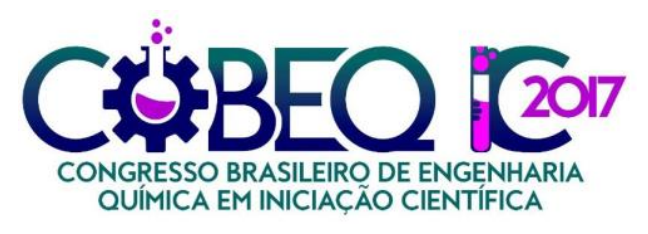

\title{
DESENVOLVIMENTO DE REATOR FOTOCATALÍTICO PARA TRATAMENTO DE GASES CONTAMINADOS COM COMPOSTOS ORGÂNICOS VOLÁTEIS
}

\author{
G. N. GARCIA ${ }^{1}$, L. A. DINIZ ${ }^{1}$, D. MATSUMOTO ${ }^{1}$ e A. C. S. C. TEIXEIRA ${ }^{1}$ \\ ${ }^{1}$ Escola Politécnica da Universidade de São Paulo \\ E-mail para contato: gabriel.negrelli.garcia@usp.br
}

RESUMO - Dentre os poluentes mais comuns nos ambientes urbanos, os Compostos Orgânicos Voláteis (COV) merecem atenção especial, pois têm efeitos negativos tanto sobre a saúde da população, quanto sobre o meio ambiente. Industrialmente, sua remoção é feita através da incineração, que tem como desvantagens alto custo de investimento e elevado gasto energético. Uma alternativa são os Processos Oxidativos Avançados (POA), que vêm sendo testados para sistemas gasosos. O presente trabalho trata do desenvolvimento de um reator fotocatalítico que utiliza $\mathrm{TiO}_{2}$ suportado em sílica como catalisador e radiação ultravioleta como fonte de energia. Este reator foi utilizado para estudar a degradação de ar contaminado com tolueno. Os resultados obtidos indicaram atividade do catalisador para degradação deste poluente. Todavia, observou-se também a desativação dos sítios ativos do catalisador por ação do benzaldeído, um intermediário da reação. Testes futuros serão realizados para otimizar a operação do reator e identificar alternativas que minimizem este efeito de desativação.

\section{INTRODUÇÃO}

De acordo com dados do DENATRAN, as frotas veiculares têm aumentado rapidamente nos últimos anos, como consequência do desenvolvimento das cidades. Segundo relatório de 2015 da CETESB, os principais poluentes emitidos no Estado de São Paulo são monóxido de carbono (CO), óxidos de nitrogênio (NOx) e hidrocarbonetos (HC). Alguns destes hidrocarbonetos recebem o nome de compostos orgânicos voláteis (COV). Ao serem oxidados em uma reação com o NOx também presente na atmosfera, os COV levam à produção de ozônio troposférico, que é causador de doenças respiratórias e produz efeitos negativos sobre a fauna e a flora.

Segundo Rochetto (2012), a nível industrial, a remoção de COV é comumente feita com incineração, que tem como desvantagens o alto investimento inicial, elevado gasto energético e a necessidade de grandes quantidades de poluente para justificar seu funcionamento. Os chamados Processos Oxidativos Avançados (POA), em especial, têm sido estudados para remoção de COV da fase gasosa, dado seu sucesso no tratamento de efluentes líquidos. Estes processos utilizam espécies altamente reativas de oxigênio para degradar os poluentes. Dentre os POA mais comumente aplicados em fase gasosa, destacam-se os processos UV-ozônio e de fotocatálise heterogênea. Este trabalho dedica-se ao estudo da fotocatálise heterogênea como alternativa para a degradação de COV aromáticos. 


\subsection{PROCESSOS OXIDATIVOS AVANÇADOS (POA)}

Dentre os diversos métodos utilizados para tratamento de COV, o processo fotocatalítico heterogêneo envolvendo radiação ultravioleta e um catalisador de dióxido de titânio $\left(\mathrm{TiO}_{2}\right)$ tem recebido atenção nas últimas décadas. Segundo Park et al. (2011), a preferência pelo $\mathrm{TiO}_{2}$ tem origem em seu baixo custo, biocompatibilidade e não-toxicidade. Em semicondutores, como o $\mathrm{TiO}_{2}$, a banda de valência é energeticamente separada da banda de condução pela energia de banda proibida. Isto significa que para que os elétrons de valência do semicondutor possam passar para a banda de condução, eles devem receber a energia de banda proibida de alguma fonte externa. Na fotocatálise, tal fonte é a radiação eletromagnética. A razão está na lei de Planck (equação 1) que relaciona o comprimento de onda da radiação com a energia de seus fótons.

$$
E_{\lambda}=\frac{h c}{\lambda}
$$

Segundo Park et al. (2011), a estrutura cristalina do $\mathrm{TiO}_{2}$ mais comumente utilizada em fotocatálise é a anatase, por conta da sua energia de banda proibida ser da ordem de 3.2 eV (Reddy et al., 2002), que corresponde a uma radiação de comprimento de onda de, aproximadamente, $387 \mathrm{~nm}$. Fótons com comprimento de onda menor ou igual a este são capazes de satisfazer este limite energético, pois a energia de um fóton é inversamente proporcional a seu comprimento de onda.

Quando os elétrons do semicondutor são promovidos para a banda de condução, eles deixam uma vacância eletrônica, de carga positiva, na banda de valência. Estes elétrons participam de reações de redução, enquanto as vacâncias participam de reações de oxidação. Tais reações oxidativas geram espécies reativas de oxigênio, que têm como principais características a não-seletividade e a alta reatividade. São estas espécies que reagem com os poluentes adsorvidos no catalisador e podem chegar até a mineralizá-los, isto é, convertê-los em gás carbônico e água (Rochetto, 2012; Park et al., 2011).

Por conta desta relação que existe entre a radiação e a ativação das reações fotocatalíticas, é desejável que a exposição das partículas de catalisador para a radiação seja a maior possível (Park et al., 2011). Essa maximização é feita através do processo de fluidização, que é a operação pela qual partículas sólidas são levadas a um estado em que se comportam como um fluido. Apesar de suas vantagens como fotocatalisador, o dióxido de titânio classifica-se como Geldart $\mathrm{C}$, sendo assim inadequado para operações de fluidização. Por este motivo, ele deve ser impregnado sobre um suporte como carvão ativado ou sílica para que possa ser fluidizado (Park et al., 2011; Asiltürk et al., 2012).

Este artigo descreve a construção de um reator fotocatalítico de leito fluidizado circulante e a verificação de sua viabilidade para degradação de poluentes atmosféricos. $\mathrm{O}$ catalisador empregado foi $\mathrm{TiO}_{2}$ impregnado em sílica gel e os poluente estudado foi tolueno. A fonte de radiação foi uma lâmpada Philips UV-C $75 \mathrm{~W}, \lambda=254 \mathrm{~nm}$. 


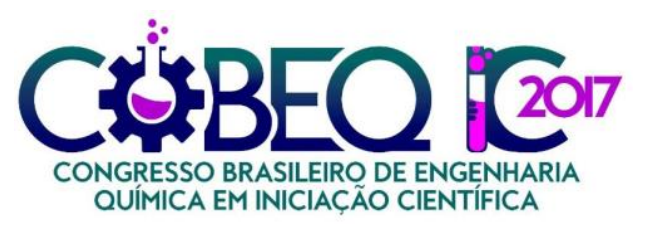

XII Congresso Brasileiro de Engenharia

Química em Iniciação Científica

UFSCar - São Carlos - SP

16 a 19 de Julho de 2017

\section{MATERIAIS E MÉTODOS}

\subsection{REATOR FOTOCATALÍTICO}

$\mathrm{Na}$ figura 1, estão representados os componentes do sistema e as etapas do processo estão brevemente descritas.

Figura 1 - Diagrama do sistema com as etapas do processo destacadas.

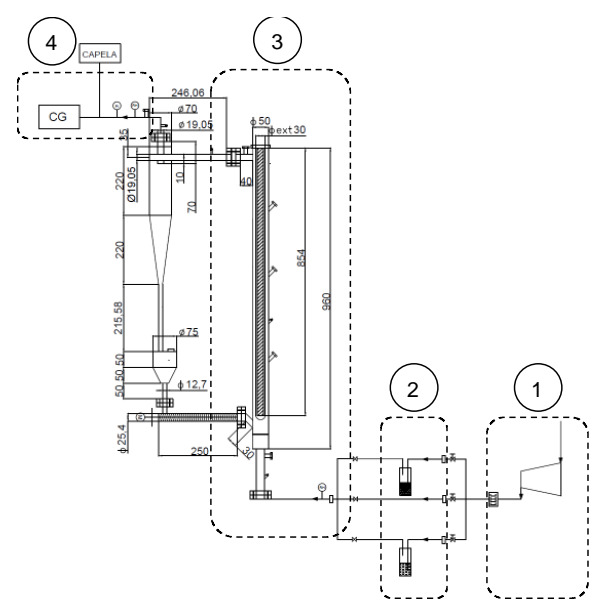

\section{Etapasdo processo}

1. Compressão a 0,08 atm e desumidificação;

2. Contaminação do ar seco com o poluente de interesse e umidificação;

3. Degradação dos poluentes pela passagem no reator, com retirada de amostras para análise;

4. Análise em cromatógrafo a gás das amostras retiradas na entrada, saída e ao longo do reator.

Além do reator, o sistema é composto por um ciclone, utilizado para capturar os sólidos arrastados do leito do reator, e por uma rosca de transporte, que os reinsere no reator.

A fonte de radiação utilizada é uma lâmpada germicida UV-C 75W (TUV36 4P T5 HO Phillips), com pico de emissão em $254 \mathrm{~nm}$. Na entrada do reator, há um sensor de temperatura e umidade DHT22 (0-5V, Arduino), cuja medição foi validada por um termo-higrômetro comercial (Digital Sling). O volume útil irradiado do reator é de, aproximadamente, $1070 \mathrm{~mL}$.

A quantificação de COV no reator foi realizada por amostragem em septos posicionados ao longo do reator com seringa gas-tight $(50 \mu \mathrm{m}$, Hamilton) e análise por cromatografia gasosa (CG, Thermo-Fisher) com detector de ionização fotoquímica (Photochemical Ionization Detector, PID) e coluna TR1.

\subsection{SÍNTESE DAS PARTÍCULAS DE CATALISADOR}

A síntese das partículas de sílica impregnada com $\mathrm{TiO}_{2}$ seguiu a rota descrita por Chen et al. (2004). A síntese foi feita para catalisador com $11,1 \%$ mássico de $\mathrm{TiO}_{2}$. Realizou-se a diálise da solução em água destilada pela utilização de uma membrana de acetato de celulose. Após 24 horas, a solução apresentou pH próximo ao neutro. Em seguida, a solução foi levada a um forno a $90^{\circ} \mathrm{C}$, onde foi secada por 48 horas. Por fim, a calcinação dos sólidos secos foi feita a $400^{\circ} \mathrm{C}$ por 2 horas, obtendo-se, assim, catalisador contendo a fase anatase do $\mathrm{TiO}_{2}$. 


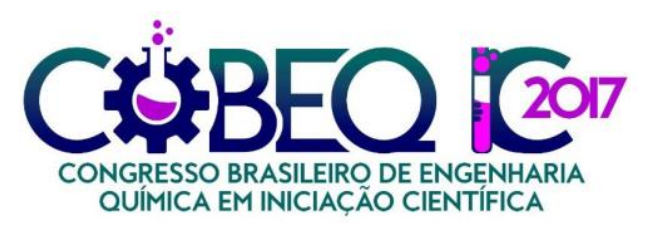

XII Congresso Brasileiro de Engenharia Química em Iniciação Científica

UFSCar - São Carlos - SP

16 a 19 de Julho de 2017

\section{RESULTADOS EXPERIMENTAIS E DISCUSSÃO}

\subsection{CARACTERIZAÇÃO DAS PARTÍCULAS DE CATALISADOR}

A caracterização das partículas de catalisador foi feita através de: DRX (Difração de Raios-X), para detecção da estrutura cristalina de $\mathrm{TiO}_{2}$ presente; e de MEV (Microscopia Eletrônica de Varredura), para verificação visual da qualidade do recobrimento.

O gráfico 1 apresenta os resultados do DRX realizado para três amostras: uma de sílica gel pura, com tamanho de partícula entre 40 e $63 \mu \mathrm{m}$; uma de $\mathrm{TiO}_{2}$ com fase anatase predominante; e uma da sílica gel impregnada com $\mathrm{TiO}_{2}$ segundo a rota apresentada no item 2.2. Segundo Chen et al. (2004), o pico presente em $2 \theta=25,3^{\circ}$ corresponde ao $\mathrm{TiO}_{2}$ com fase anatase. Além disso, um pico em $2 \theta=27,4^{\circ}$ corresponderia à presença de rutilo. Como o pico em $25,3^{\circ}$ é observado e o pico em $27,4^{\circ}$ não é, pode-se concluir que predomina $\mathrm{TiO}_{2}$ na forma cristalina anatase.

Gráfico 1 - Resultados de DRX para sílica gel pura, $\mathrm{TiO}_{2}$ na forma anatase e para sílica gel impregnada com $\mathrm{TiO}_{2}$.

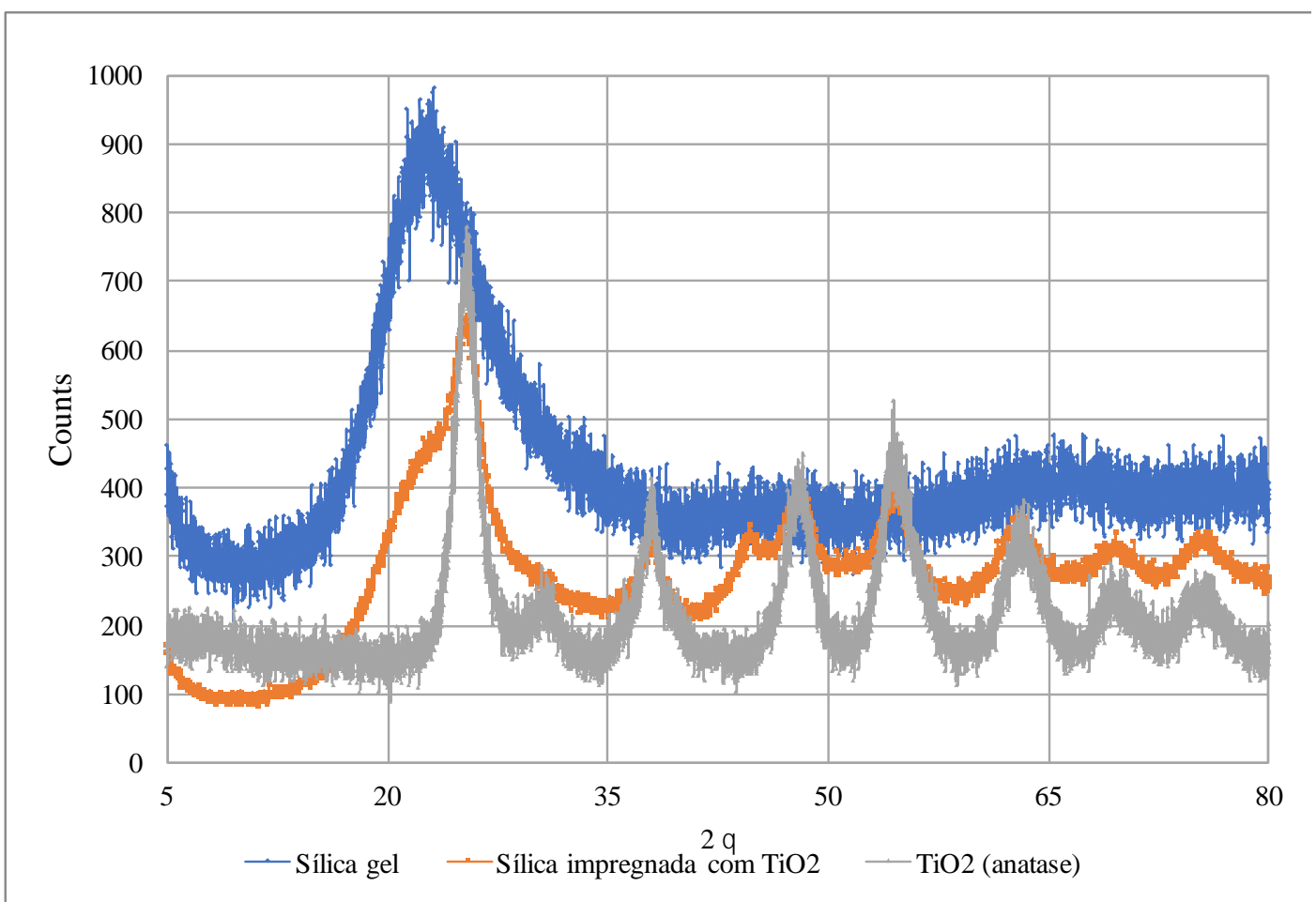

$\mathrm{Na}$ figura 2, apresenta-se a análise feita em MEV de duas amostras de material do catalisador. A identificada como (a) contém sílica gel pura, isto é, sem impregnação. A identificada como (b) apresenta $\mathrm{TiO}_{2}$ sob a forma de um recobrimento sobre as partículas de sílica. 


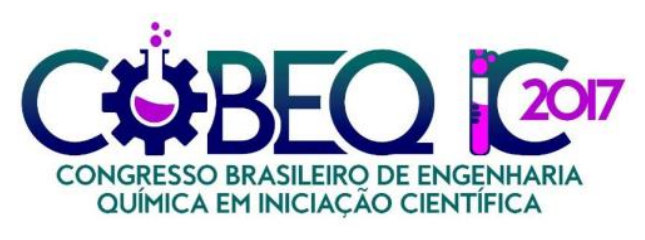

XII Congresso Brasileiro de Engenharia

Química em Iniciação Científica

UFSCar - São Carlos - SP

16 a 19 de Julho de 2017

Figura 2 - Resultados obtidos com MEV para: a) amostra de sílica gel pura; b) amostra de sílica gel impregnada com $\mathrm{TiO}_{2}$.

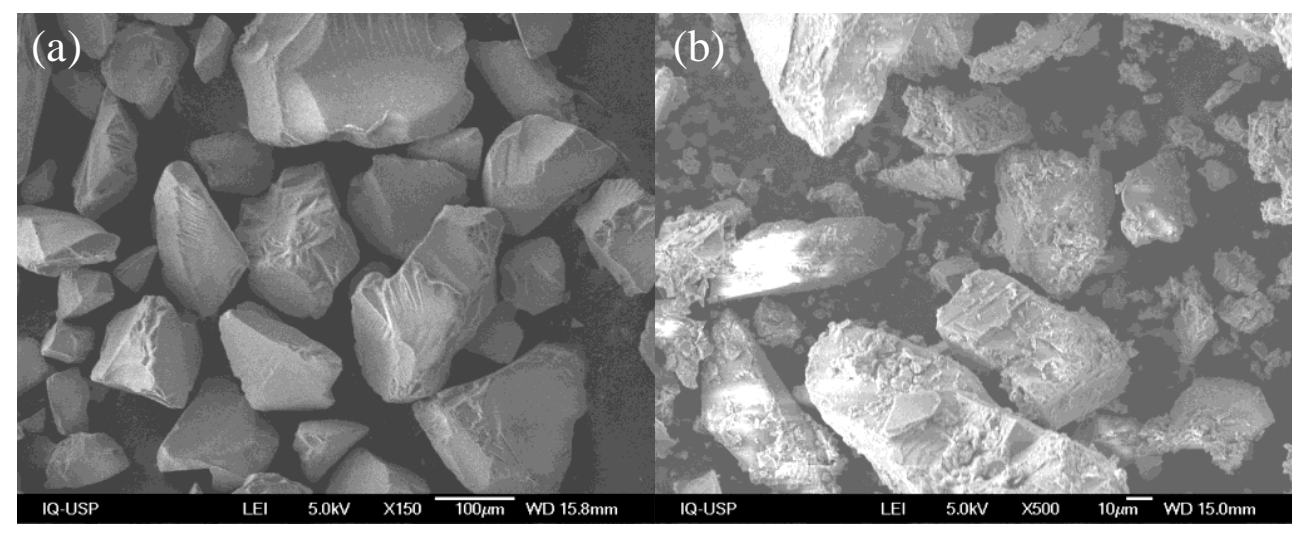

\subsection{TESTE DE ATIVIDADE DO CATALISADOR}

Para o caso do tolueno, foi realizado um ensaio em que o reator foi preenchido com $100 \mathrm{~g}$ de compósitos $\mathrm{TiO}_{2} / \mathrm{SiO}_{2}\left(20 \% \mathrm{TiO}_{2}\right)$ em condições de alta carga de entrada de tolueno com o objetivo de verificar o efeito de desativação do catalisador. Neste ensaio, o reator foi operado como leito fluidizado circulante em modo contínuo a uma vazão de $20 \mathrm{~L} \mathrm{~min}^{-1}$ e concentração de entrada de 3900 ppmv. A evolução deste ensaio é mostrada na Figura 3. Após o acionamento da lâmpada, em $\mathrm{t}=0 \mathrm{~min}$, foi possível observar degradação de $18 \%$ do tolueno na corrente de entrada do reator, confirmando a atividade do catalisador. Além disso, após $\mathrm{t}=40$ min observa-se que não há diminuição da concentração de saída, o que indica a desativação total do fotocatalisador por envenenamento de seus sítios ativos. Através de extração com metanol e análise em cromatografia gasosa com espectrometria de massas, verificou-se que o intermediário responsável pela desativação foi o benzaldeído.

Figura 3 - Evolução temporal do ensaio de degradação fotocatalítica de tolueno em condições de alta carga de entrada (20 $\left.\mathrm{L} \mathrm{min}^{-1}, 3912 \pm 248 \mathrm{ppmv}\right)$.

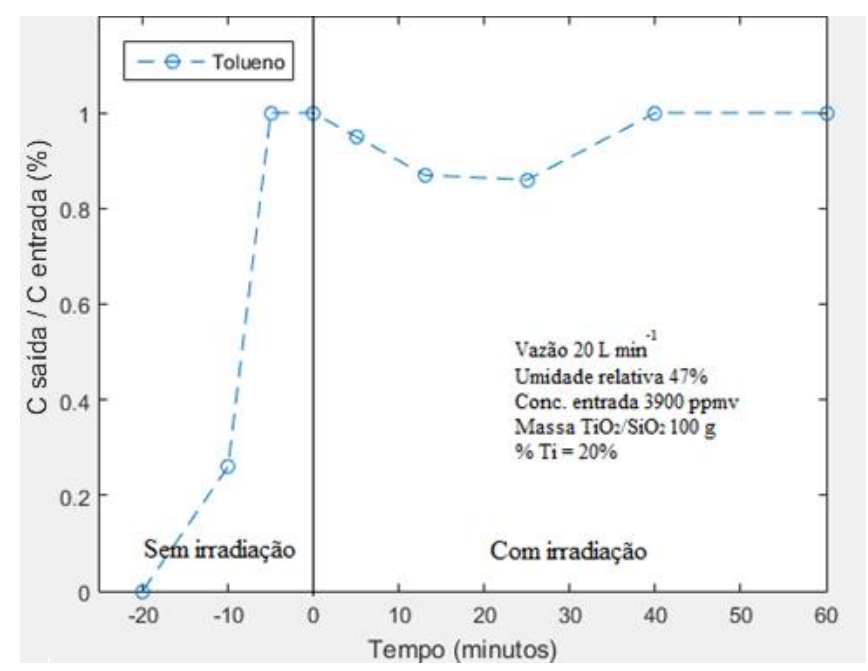




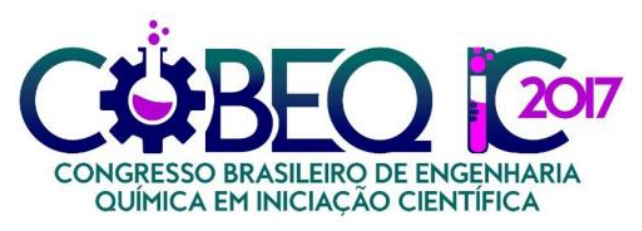

XII Congresso Brasileiro de Engenharia

Química em Iniciação Científica

UFSCar - São Carlos - SP

16 a 19 de Julho de 2017

\section{CONCLUSÕES}

Através das análises realizadas para o catalisador, conclui-se que a rota proposta por Chen et al. (2004) produz partículas de $\mathrm{TiO}_{2}$ impregnado em sílica gel de modo eficaz. Além disso, os ensaios preliminares demonstraram que o processo é viável para a degradação de tolueno de uma corrente de ar contaminada. Outros estudos serão realizados visando a otimizar a operação do reator fotocatalítico em leito fluidizado e a estudar alternativas para minimizar os efeitos de desativação do fotocatalisador.

\section{NOMENCLATURA}

$\lambda$ - comprimento de onda (em m);

$\mathrm{h}$ - constante de Planck $\left(6,626.10^{-34} \mathrm{~m}^{2} \mathrm{~kg} \mathrm{~s}^{-1}\right)$;

$E_{\lambda}$ - energia de um fóton (em J) de comprimento de onda $\lambda$;

c - velocidade da luz no vácuo $\left(2,998 \cdot 10^{8} \mathrm{~m} \mathrm{~s}^{-1}\right)$.

\section{REFERÊNCIAS BIBLIOGRÁFICAS}

ASILTÜRK, M.; ŞENER, Ş.; TiO2-activated carbon photocatalysts: Preparation, characterization and photocatalytic activities. Chemical Engineering Journal, v. 180, p. 354-363, 2012

CETESB, Relatório de qualidade do ar no Estado de São Paulo - 2015, São Paulo. Disponível em: <http://ar.cetesb.sp.gov.br/wp-content/uploads/sites/37/2013/12/RQAR-2015.pdf>

CHEN, Y.; WANG, K.; LOU, L.; Photodegradation of dye pollutants on silica gel supported TiO2 particles under visible light irradiation. Journal of Photochemistry and Photobiology, v. 163, p. 281-287, 2004

DENATRAN. Frota de veículos - 2006 a 2015. Disponível em: <http://www.denatran.gov.br/index.php/estatistica/237-frota-veiculos>

PARK, J.-H.; SEO, Y.-S.; KIM, H.-S.; KIM, I.-K.; Photodegradation of benzene, toluene, ethylbenzene and xylene by fluidized bed gaseous reactor with $\mathrm{TiO}_{2} / \mathrm{SiO}_{2}$ photocatalysts. Korean J. Chem. Eng., v. 28, p. 1693-1697, 2011

REDDY, K. Madhusudan; MANORAMA, S. V.; REDDY, A. Ramachandra; Bandgap studies on anatase titanium dioxide nanoparticles. Materials Chemistry And Physics, v. 78, p. 239-245, 2002

ROCHETTO, Ursula Luana. Degradação de compostos orgânicos voláteis em fase gasosa por fotocatálise heterogênea com TiO2/UV. 2012. 127 f. Dissertação de Mestrado Universidade Estadual de Campinas, Campinas, 2012. 